\title{
Community Action-Based Field Work: Training Counselors to Become Social Agents in Schools and Communities
}

\author{
Adonay Antonio Montes \\ University of La Verne
}

Laurie Schroeder

University of La Verne

\begin{abstract}
The requirement to complete field work hours as "action based pedagogy" allowed candidates in a school counseling program to broaden their cultural perceptions of diverse groups by engaging in action research projects of their own choosing, led by their interest in and commitment to becoming familiar with diverse populations of $K-12$ students. This assignment allowed candidates to immerse themselves in culturally rich schools as researchers to understand better the experiences of diverse students. In the planning and implementation of these projects, the school counseling trainees deconstructed cultural barriers, changed their perceptions and preconceived stereotypical notions about diverse groups and gained social advocacy skills for use in their work as professional counselors supporting the academic and aspirational growth of minority students. Candidates also became familiar with multicultural literature and resources available concerning diverse populations.
\end{abstract}

Key words: social agency; community-based activities; multiethnic communities;

cultural barriers; action research

Adonay Antonio Montes, Ph.D., is Assistant Professor in the MS in Educational Counseling and PPS Credential Program in the College of Education and Organizational Leadership at University of La Verne in California. He is also the Director of the Spanish Bilingual Bicultural Certificate Program.

Laurie Schroeder, Ph.D. is Associate Professor in the College of Education and Organizational Leadership at University of La Verne in California. She is Chair of the MS in Educational Counseling, PPS Credential Program, and Chair of the Advanced Studies in Education and Human Development Department.

Email: amontes@1averne.edu

Brock Education, Volume 21, No. 1 Fall, 2011, 63-83 


\section{Introduction}

As the $21^{\text {st }}$ century unfolds, appraising the context in which school counselors practice as well as the new challenges and opportunities for growth in new educational learning environments plays an important role in better serving the needs of schools' student cultural mosaic (Sue, Arredondo \& McDavis, 1992). Preparing candidates to work within the evolving demographics in schools and communities nationwide calls for graduate level educational counseling programs to provide candidates with training to develop crosscultural pedagogical practices that meet the needs of our emerging diverse populations (Gysbers, 2001). These practices are best developed through a process whereby candidates learn the challenges faced by multicultural communities of learners in schools and generate pedagogical practices that lead to individual and group interventions designed to ensure the success of target populations with particular problems (Petr \& Walter, 2005). Candidates in this study's educational counseling program actively engaged in actionbased research as a component of their fieldwork requirement, in which candidates had an opportunity to apply theory learned in the classroom to practice, assess the effectiveness of individualized and group interventions, gain knowledge of and experience with the corresponding sociocultural and educational realities of diverse students, break down their own cultural misconceptions, develop multicultural sensitivity and competence, and cultivate a mindful and organic connection with the profession of school counseling.

\section{Literature Review}

The goal of school counselors is to work with students, parents, teachers and administrators to ensure that students' academic, personal/social and career needs are being met (Adelman \& Taylor, 2002). Green and Keys (2001) note that typically school counselors are perceived as problem solvers or professionally trained educators who help parents and students reach viable solutions to alleviate their concerns. This perception of school counselors has held true until the most recent changes in school demographics (Green, Conley \& Barnett, 2005).

New challenges in educational and social cultures call for commitment and creativity from educators and candidates in educational counseling preparation programs (Education Trust, 2007). Schools are experiencing an extensive demographic transformation requiring innovative pedagogical counseling practices (House \& Hayes, 2002). Historically, school counseling was crafted under the social reform movement of the $19^{\text {th }}$ century. However, with the growing interest in serving the needs of diverse learners, the focus of school counseling has evolved into a comprehensive, developmental, and collaborative approach following the National Standards adopted for School Counseling Programs (Martin, 2002). This sociocultural evolution has reshaped the role of school counselors from that of simple academic and behavioral guides to schoolcommunity counselors and student advocates in the $21^{\text {st }}$ century (Paisley \& McMahon, 2001).

Changes in the counseling profession are led by the focus placed on academic, 
career, and personal/social domains as well as societal changes, standardized testing expectations, and other complex issues facing schools, communities, families, and students (American School Counselor Association, 2005). As the $21^{\text {st }}$ century unfolds, appraising the context in which school counselors practice as well as the new challenges and opportunities for growth in new environments plays an important role in better serving the needs of schools' student cultural mosaic (Sue, Arredondo, \& McDavis, 1992). School counseling preparation programs must take responsibility for addressing the evolution of demographics and other pressing sociocultural issues affecting our neighborhoods by preparing counseling candidates with an excellent foundation in multicultural counseling, communication and group processes as well as skills in consultation, collaboration, intervention and program evaluation in relation to school counseling services (Perusse, Goodnough \& Noel, 2001).

Preparing candidates to work within the evolving demographics in schools and communities nationwide calls for graduate level educational counseling programs to provide candidates with training to develop cross-cultural pedagogical practices that meet the needs of our emerging diverse populations (Gysbers, 2001). The rising needs of newly found multicultural communities call for assignments involving action-research practices designed to ignite active conversations and interactions with local communities (Dickson \& Jepsen, 2007). In action research, candidates, students and parents become the foundation of a learning process whereby all participants collectively generate new knowledge that considers and honors the value of their culturally existential trajectories (Epstein, 2008).

Candidates in this study's educational counseling program are required to complete 600 hours of fieldwork. In actively engaging in action based research as a component of their fieldwork requirement, candidates have a valuable opportunity to apply theory learned in the classroom to practice; assess the effectiveness of individualized and group interventions; gain knowledge of and experience with the corresponding sociocultural and educational realities of diverse students; break down their own cultural misconceptions; develop multicultural sensitivity and competence; and cultivate a mindful and organic connection with the profession of school counseling.

\section{Cultural Specialist: Awareness-theory-growth-skills}

The inseparability of school and community is a prevalent variable in the development of community-based action research projects (Sanders \& Lewis, 2005). The purpose of having candidates engage in action-based projects is twofold. First, to provide learning opportunities that are culturally appropriate, for we have an increasing number of students with worldviews that are markedly different from counselor candidates (DeLucia-Waak, 1996). Second, to prepare candidates with an action-based process allowing them to gain personal cultural insight through a three-stage process (Dickson, Jepsen \& Barbee, 2008): a) enhancement of knowledge and experiential bases, b) engagement in self-reflection, growth and development, and c) acquisition of mental and emotional readiness and social agency. Thus, becoming a reflective practitioner encourages the augmentation of professional competence, self-understanding and sensitivity, and systemic understanding. 
Appreciation for the richness of diverse cultures, a clearer understanding of one's own culture, and knowledge of how cultural factors influence cognitive, behavioral and emotional responses to experiences and perceptions in school and communities are also enhanced (Anderson-Butcher \& Ashton, 2004).

The intent behind community-based action research is to incorporate an ethnographic methodology whereby candidates develop a culturally driven purpose, allowing them to become agents of social change based on their own personal development and compassionate sensitivity to the needs of others. This developing purpose informs their learning and action processes (Christenson \& Sheridan, 2001). Social agency (Dahir \& Stone, 2009) is encouraged in the 'aula' by creating action plans that promote the use of critical thinking and multicultural pedagogy. Zaida (2005) defined social agency as a method that establishes partnerships between schools and the community, unlocks individualization, and aims to achieve universal high standards.

The process of carrying out (figure 1) action-research initiatives to accomplish the previously mentioned goals includes a journey through four quadrants. Action research was selected due to the need for candidates to find responses to their questions and improve practices along the way without waiting for a final resolution (Elliott, 1991). Generating immediate responses through reflection and journaling to all of the questions that emerged throughout the study created a process of construction knowledge (Greenwood \& Levin, 2007), which was the key to increasing student achievement.

\section{Figure 1}

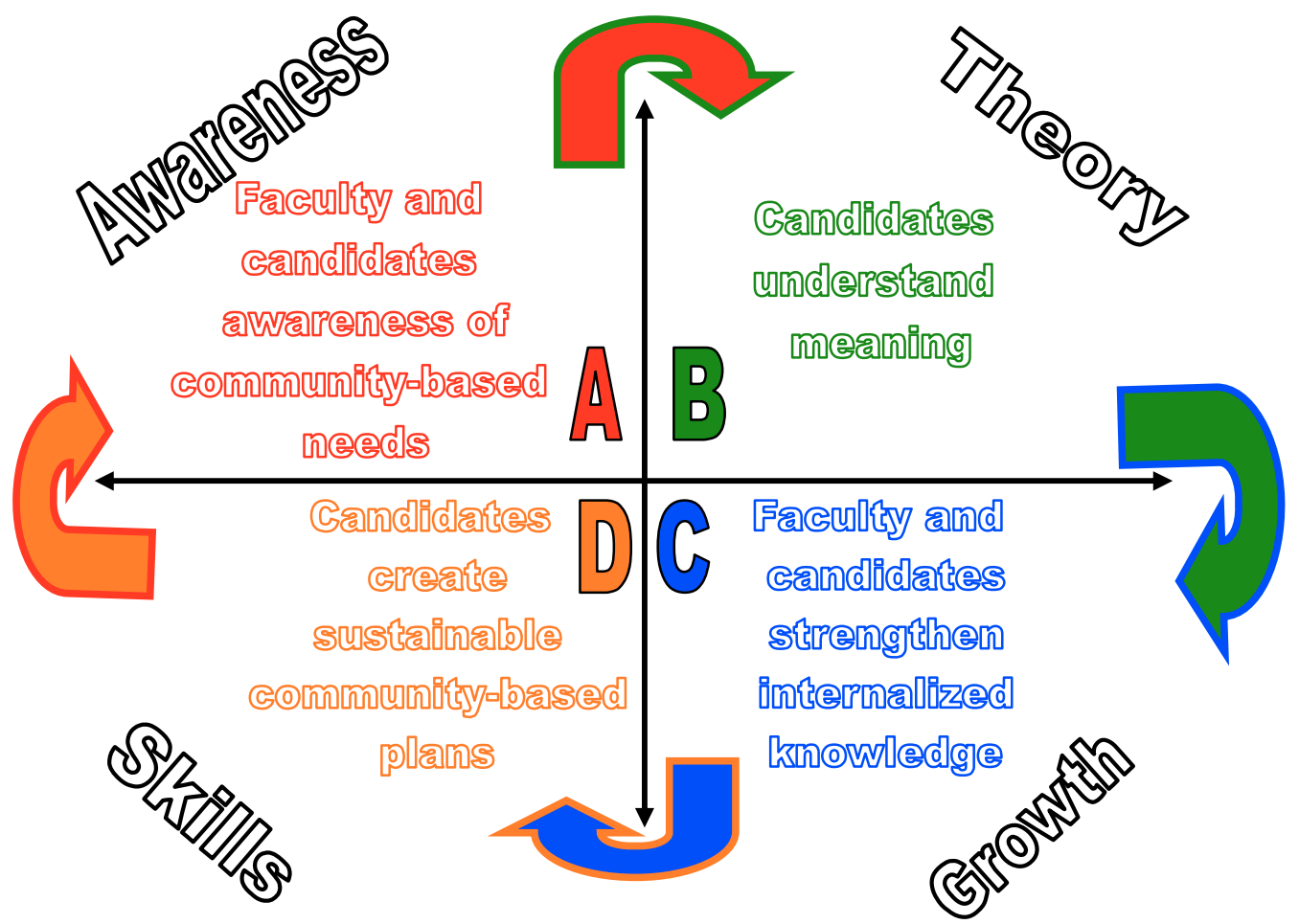


In this journey, faculty and candidates begin their building process in quadrant $\mathrm{A}$, a space where faculty facilitates and guides the analysis of differences between communitybased needs in multiethnic neighborhoods with the goal of creating awareness and a knowledge base in candidates that translates into action plans developed through interactions among candidates. Community-based needs are analyzed with the common understanding that difference, as defined by Sue and Sue (1990), is "the identification of sharing, cooperation, non-interference, time orientation and harmony with nature". With these five elements, candidates begin to develop the 'practical framework' of their action plans. At this stage, candidates and faculty work cooperatively in order to create a community of educational bricoleurs (Denzin \& Lincoln, 2003) that searches for the preliminary woven strands of a communal knowledge expressed with the strategies, methods, or empirical materials at hand. Following this first phase, students move to quadrant B, where they work independently to create meaning by comparing and contrasting their thoughts, constructed during the preliminary discussions, with those of their peers.

Soon after candidates have internalized their meanings, faculty continue to work collaboratively with candidates to strengthen the theory that supports and further informs their findings. Based on the funds of knowledge gained in their fieldwork experiences with their respective diverse group(s), candidates construct action plans (Marshall \& Toohey, 2010) that will have an impact on their work with students and in their communities. At this point, the new generation of transforming social agents is required to share the outcomes and impact of fieldwork experiences with fellow candidates through classroom presentations where they illustrate their understanding of the inseparability of school, family, community, and cultural richness, and how disruption in one of these systems affects all of the others (Bemak, 2000). The knowledge gained in respect to the influence of societal issues on schools, families, and communities (institutional racism, oppression, economic standing, and violence) is also shared.

In the last phase, counseling candidates reconstruct an approach based on personal development, cultural competency and responsiveness to the diverse needs of cultural mosaic communities and schools (Bryan, 2005). They share strategies, skills, and resources gained during their fieldwork journeys with their colleagues. All of the participants complete the circle around the four quadrants, beginning with the collective cooperative analysis of pressing community-based needs in order to generate action plans and how these can be implemented in their communities. Later, they ground their practical framework with 'dynamic theory of real community work' (Epstein \& Voorhis, 2010). Finally, they come back to praxis by developing projects they can implement in local communities and establishing networks for meaningful affiliations both within and outside their communities (Kretzmann \& McKnight, 1993).

\section{Why Action-Based Field Work}

Our position is that prospective counseling educators in credentialing programs need to implement fieldwork with community-based activities in order to acquire a comprehensive pedagogy nourished by the deconstruction of knowledge generated in multiethnic 
communities (Bemak, 2000). The model presented asked counseling candidates to develop projects that analyzed the individuality of students and parents, but also acknowledged and honored the deep cultural values they each bring to Southern California schools. Later, they incorporated the knowledge they gained into their daily practices in the development of multicultural practices and development of educational roadmaps (Mason, 2008). In conducting these projects, candidates exposed themselves and others to a new dimension of counseling, one that empowers and expects educators to expand local and state standards to a multiglobal perspective. While learning about the community from the inside out, transforming counseling educators became competent within the holistic context that the cultural, physical, mental, social and humanistic conditions of students, parents, and educators are what defines them as full members of the global village (Kretzmann \& McKnight, 1993).

\section{Action Research in Fieldwork as a Form of Pedagogical Development}

The value of fieldwork education is priceless; it offers an ideal opportunity for candidates to get an inside view of the challenges faced by diverse students in k-12 schools (Herring, 1998). However, candidates need to be prepared to value the richness of doing work in multicultural communities in order to gain the depth of knowledge needed to develop best practices that will meet the goals and aspirations of students in multiethnic schools (Holcomb-McCoy, 1998). We define best practices as the process whereby candidates learn the challenges faced by multicultural communities of learners in schools and generate pedagogical practices that lead to individualizations and group interventions designed to ensure the success of target populations with particular problems (Petr \& Walter, 2005). Additionally, we find it valuable for candidates to have access to the wisdom of culturally diverse groups; they become part of the learning process by engaging in dialogue with students, parents, community members and other stakeholders.

The quest to train school counseling candidates to become effective social change agents entails fostering their desire to nurture relationships between themselves and the schools and communities where they will work (Ellis \& Bochner, 2000). We believe that building relationships with schools, communities and community members is a significant skill set for candidates. The goal is to allow candidates to cultivate healthy working relationships, understanding, empathy, respect, and appreciation for the cultural and academic capital of students, parents and community stakeholders (Tedlock, 2000).

The cultural metamorphosis of education and the application of cultural theory have guided the construction of a community-based fieldwork model, a model that continuously searches for multicultural pedagogy that provides communities of learners with a multidimensional methodology of counseling. This methodology assures that participants have access to the many factors that support and bolster their academic success and increases the participation of other community stakeholders in local neighborhoods (McNiff, 1988). This model also serves as a means for candidates to engage in self-reflection, recognize the individuality of clients, and acknowledge the deep cultural values held by the clients. The objective of the model is to encourage and support candidates in becoming cultural specialists with knowledge, experiential bases and 
awareness of cross-cultural issues affecting the educational trajectories of learning communities in schools (Dickson \& Jepsen, 2007).

Validating the importance of the cultural richness of participants ensures that the learning process for all entities does not become stagnant or lack the cultural references that are indispensable in creating a model of comprehensive education that addresses the multicultural needs of all members (Constantine \& Yeh, 2001). In the context of counseling in the school environment, diversity has been reconstructed as multicultural growth in a synergetic process actively involving candidates and communities, rather than a standardized process where diverse communities are seen as colorless canvas without a personal cultural essence (Green \& Keys, 2001). Pedagogical practices fomented by this model in the aula challenge the monochromatic view of polychromatic enclaves typically contextualized from a one-dimensional Eurocentric perspective on the basis of needs, deficiencies and problems (Corey, 2004). Transformational counseling candidates must see themselves as educational artists rather than instructional technicians. With this perspective, they can begin to reconstruct the colorless perceptions of community-based knowledge and cultural richness by generating action-research assignments (Erford, 2003) and moving beyond "the assumption that a theory can be rather directly expressed in action" with a genuine commitment to the discovery and appreciation of vernacular voices and their assets. The outcome will be an expansion of theoretical pedagogy for counseling practitioners (Constantine, Arorash, Barakett, Blackmon, Donelly \& Edles, 2001).

\section{Methods}

A qualitative approach was deemed the most effective means by which to address the objectives of the study. The focus was on exploring the candidates' cultural perceptions of diverse populations, the meaning they gave to their fieldwork experience, the introspective process of their experience, how this experience shaped their inner counseling voices, and the acquisition of social advocacy skills for use in their professional careers as school counselors (Lincoln \& Guba, 1985). A qualitative approach allowed the researchers to document the transformative process that candidates undergo, whereby their realities are deconstructed as they engage in action research projects with culturally rich groups in multiethnic communities (Ponterotto, 2005).

In the spectrum of qualitative methods, the researchers determined that an interpretive phenomenology approach was a match for this inquiry because we were specifically exploring the impact of action research projects embedded in fieldwork, and their potential for creating a broad range of transformative meanings (Creswell, 2007). The primary goal of a phenomenological approach is to gather data from individuals about their conscious awareness of specific experiences, in this case, their fieldwork experiences and to describe the essence of that awareness as reflected through the voices of the participants (Moustakas, 1994; Van Manen, 1990). Hermeneutic phenomenology, in particular, focuses on the lived experience, highlighting the growth of awareness generated from the lived experience (Heidegger, 1962).

In this study, the lived experience was that of school counseling candidates, provided 
by their written analyses of their action-based fieldwork projects. The written narratives met the criteria of phenomenological data that (a) included participants' self-reflection, (b) recognized the individuality of diverse groups, (c) acknowledged the deep cultural values held by the diverse clients, and (d) represented a willingness to talk about experiences gained in this process (Laverty, 2003). This research design is consistent with the therapeutic construct that individual growth begins with the internal exploration of the individual within his or her context (Granello, 2000; O'Byrne \& Rosenberg, 1998) and with the view as both researchers and educators that learning is a synergetic process rather than a solely individual process (Stahl, 2006).

\section{Context}

Thirty-six graduate students pursuing a master's degree in a School Counseling Program at a university in the Southern California took part in this action-based study. They were given the option of selecting a diverse population they would want to learn about in public school settings at elementary, middle, or high schools. Part of the assignment included completing thirty hours of fieldwork as ethnographers in the school, community, and other pertinent settings related to the population researched. At the end of their fieldwork hours, candidates put together a ten-page narrative illustrating their key learnings. The data gathered was unique because it revealed the transformative process of candidates as they interacted in their diverse settings.

\section{Standards of Trustworthiness and Authenticity}

Credibility, dependability, confirmability, and transferability of the findings are key elements in qualitative research (Guba \& Lincoln, 1989). Credibility was achieved through our active involvement in the design of and inquiry into the narratives, which was based on the auto-ethnography of each of the participants. Both researchers were involved in the data analysis process, immersing themselves in the data. The research team in this study worked as a cohesive unit, collaborating throughout the entire research process. Our collaboration mirrored the insider/outsider perspective of the researcher in qualitative inquiry (Suzuki, Ahluwalia, Arora, \& Mattis, 2007). Both researcher roles are significant as the insiders have an in-depth knowledge about the communities under study, and outsiders approach the study from an open, fresh standpoint with fewer preconceived ideas. The first author, an assistant professor, is a member of the school counselor preparation discipline and was the course instructor. He had an insider perspective because he planned the instruction for the group of school counseling candidates who participated in the action-based research study. The second author, an associate professor in the school counselor preparation field, was the outsider in that she was unfamiliar with details of the assignment and approached the study from an ethically professional distance (Suzuki et al., 2007 , p. 300). Each brought his or her own expertise to the research process.

Our own diverse backgrounds and our perspectives as an insider and outsider were beneficial in recognizing one-dimensional cultural references. Having a diverse research 
team enriched the multiple analytical perspectives of the data (Havercamp \& Young, 2007). In addition, the researchers each kept a reflexive journal during the process of reviewing students' projects and papers and dialogued regularly to share journal entries and perspectives as the study progressed. Students were included in the dialogue after completion of the first draft of the research paper.

"Dependability reflects the stability of the findings over time" (Guba \& Lincoln, 1989, p. 242). Guba and Lincoln (1989) pointed out that shifts in the creation and changes in the design of methodology are expected; however, such variations in the methods need to be documented. As noted previously, each researcher kept a reflexive journal, noting personal and professional thoughts and perspectives as he or she reviewed students' projects and resulting papers. Ensuing dialogue between the researchers and the students allowed for confirmation of the value and accuracy of the process as planned, as well as enhancing and deepening the researchers' understanding of the student experiences. Confirmability mirrors that the authenticity of the findings is rooted in the data, meaning that the data can be tracked to their sources, in this case the candidates' narratives (Guba \& Lincoln, 1989, p. 243).

Using Guba and Lincoln's guidelines (1989) we replaced the notion of generalizability of results with transferability of the focus of the study (pp. 122-124). As suggested in their research, rich description from the candidates' key learnings support and facilitate transferability of our findings to the readers and empirical work alike. Thus, readers and other researchers have the opportunity to decide on the degree of congruence and applicability of our work to their own teaching and learning environments.

\section{Findings}

The rationale leading to the design of this assignment is for candidates in a school counseling preparation program to gain the cultural funds of knowledge that will allow them to experience actively the daily nuances of diverse populations in school, home, and community (Singh, Urbano, Haston \& McMahon, 2010). The researchers feel this type of fieldwork project stimulates candidates to cross cultural barriers that otherwise would impede them from engaging in working with students, parents and community members in geographically underserved locations (Martin, 2002). In the narratives, the interns described and interpreted their experiences. These narratives were likely distinctive in that they differed from how the candidates would talk with site professors, thus providing a behind-the-scenes insight into how the candidates made meaning of their experiences.

Below we will identify themes that reinforce the candidates' growing awareness as they work with diverse groups in their supervised fieldwork.

\section{Emerging Themes in Action-Based Work}

Findings in this manuscript were organized according to the salient themes highlighted by candidates in their projects. Cases presented below are used to highlight each theme. 
Pseudonyms replace participant names.

\section{Violeta: Expectational Conditioning of Students}

Schools are often seen as gold mines of potential success stories of students defining their education trajectories to reach their aspirational goals and possible selves (Montes, 2007). However, the experiences of minority populations are similar in that students are forced into societal molds imposed upon them by educational stereotypes specific to their ethnic group (Pedersen \& Carey, 2003). This is reflected in how particular students are expected to graduate and go on to study in the fields of science, technology, biology, business and engineering while others are expected to become statistical examples of the lack of success in their ethnic group (House \& Martin, 1998). The accounts below describe the insights of one of the candidates, Violeta, in respect to her understanding of the educational expectations for Latino and Asian students.

Violeta is a candidate in our program who worked with Latino and Asian students, two diverse groups that exemplify a cultural polarity of academic success based on societal and educational standards. Violeta looked at the stereotypes of Latino and Asian American students and how they share the umbrella of minorities and discrimination despite the fact that their individual stereotypes could not be more disparate. Typically, Asian American students are seen as smart, over-achieving booklovers: the 'model minority' (Sue \& Sue, 2008). Their non-Asian peers, longing to replicate their success, hold Asian American students in high regard. Unfortunately, academic stereotypes for Latino students differ significantly in that they are labeled as underachievers unable to succeed in advanced course work (Santiago-Rivera, Arredondo, \& Gallardo-Cooper, 2002).

Violeta reflects in her findings that even those stereotypes that seem harmless, like the 'model minority', can hinder the self-concept of Asian American Pacific Islander students. She states, "While some Asian American students do fit the stereotype, often Asian American students find it hard to live up to the hype that has been created. Asian American students may feel as if they are not successful, simply because they are not getting the highest grade in the class or are not successful in math." In the Asian culture, education is highly valued and the parents often expect the students to value it as well. However, the pressure placed on Asian students to succeed can make it difficult for them to define their own success in schools. "Julie Loc, the daughter of a seamstress and a product truck driver, said that if she gets a B, her parents ask whether she needs tutoring" (Trevino, 2008).

On the other hand, Latino students continually receive messages from the public educational system that they lack the academic skills to succeed in school. Violeta indicates:

The educational system also does not do an adequate job of embracing the Hispanic family structure. Many educators act as if it is a chore to get a translator to try to communicate with Spanish speaking families. If students feel as if their culture and family are a burden to school, what is going to motivate them to flourish? 
Over time, the students intentionally or unintentionally will internalize and honor the low expectations and self-deprecating remarks made to them, resulting in low academic performance (Trevino, 2008). There are plenty of examples of Latino families that have high expectations and aspirations for their children. For example, in a Los Angeles Times article, "Trying to Bridge the Grade Divide", Carlos, a high school student tells the reporter about family expectations:

His mother, Maribel, from El Salvador, is a homemaker; his father, Santos, a Mexican immigrant, is a drywall finisher who once a took Carlos and his older brother to work with him - to scare them away from manual labor. Two of their children have college degrees, one is still in college and Carlos, the only Latino on Lincoln's Academic Decathlon team, wants to attend Caltech (LA Times, 2008, p. 3)

For Latino students, our educational system tends to assume that the family does not care and subsequently assumes that the student does not care. Violeta reflects, "As counselors, if we want these students to be able to succeed at whatever level they want, we need to be a liaison between the school and the structure and the community." Moreover, "schools need to create environments where both Latino and Asian students could feel welcome and able to express their own cultures". Violeta's understanding of the cultural and familial dynamics of parents and students enabled her to develop empathy for students' struggles (Latino and Asian) to meet the expectations placed upon them by blood relatives and institutional agencies.

\section{Reyna: Understanding the World of At-Risk Girls}

Working with at-risk middle school girls was a learning experience for Reyna in all aspects. She shared that her familiarity with services available for this population was minimal

And I lacked true empathy...I was raised with the idea that a good spanking would fix the root of the problem... it has become clear to me that much more needs to be done to help heal and direct our youth toward a path of success and happiness. After getting to know more about these girls I began to see them as complex individuals who were simply trying to survive and feel a sense of power and belonging.

This paradigm shift for Reyna led her to a more active role in affirming and supporting these young women. She stated, "I became the advocate for a student on several occasions because had I not, the student would have felt alone and bullied by a system that continually reminds them how imperfect they are".

Reyna found out firsthand how difficult it can be to find much needed assistance for underserved populations, noting that:

I had to quickly find out about resources available in the community. I found it to be a frustrating experience. I learned that when survival is the primal need, 
showing interest in others or doing well academically becomes secondary to many things.

As a result of her experiences, Reyna now has a deeper understanding of the lives of high-risk students and their families, and adds, "Many of these students were faced with obstacles and experiences that did not allow them to fit into a picture perfect mold. Their experiences were different than that of the average student and so were their needs".

\section{Multiculturalism in Schools}

Multiculturalism in schools is oftentimes defined in the limited paths that diverse students can take in their educational trajectories $(\mathrm{Au}, 2009)$. $\mathrm{Au}$ states that the premise of multiculturalism encompasses a larger scope, one that recognizes the need to target oppressive systematic practices that take place in schools throughout the nation. Counselor candidates, in writing about their projects made reference to the ways schools address multiculturalism. Franco stated that:

Schools profess to cultivate multicultural education, however, [in their view], multicultural education as articulated in schools is not really multicultural. Our educational institutions do not honor and respect all cultures every day. Schools focus on the premise of the 'culture of the month' one month at a time, like a holiday that comes and goes once a year.

Another candidate, Sofia, said, "I learned that working with Latino families requires an understanding of different worldviews that may impact how parents communicate with professionals as well as with their own children". Honestidad added "I always try to keep in mind the importance of each student's unique background and the importance of embracing that uniqueness with understanding". Franquesa, another candidate, further noted:

Teachers have to learn to consider all of the aspects of a student's life when trying to understand why a student is having difficulties in school... cultural background, ethnical differences, and family situations are several aspects to look at when analyzing students' progress in school.

We find the comments of candidates in this section to be of critical importance; they reflect the need to value multiculturalism, and the cultural richness of students, parents, and community members in order to promote true embracing of cultural differences.

\section{Social Agency}

School leadership, counselors, teachers, principals, classified staff and other educational stakeholders, must acquire the capacity to value diversity in ways that treat everyone with cultural appreciation and respect (Pew Hispanic Center, 2005). Social agency requires: a willingness to develop a transformative educational awareness that leads to a close 
examination of personal biases; understanding of the larger picture of the trajectories of diverse groups; and the development of and a continuing commitment to the development of proper interventions designed to make a difference in the lives of those who come from diverse backgrounds (Portes \& Rumbaut, 1990).

The words expressed by our candidates in their work articulate a vision that calls for educators to adopt a broader, more encompassing approach in working with diverse students. For example, one counselor candidate said:

We need to help all school staff members to understand that all the students have the potential to succeed at many levels. As counselors, we cannot overlook the desire and capability of an Asian American student studying nursing at a junior college rather than premed at an Ivy League institution, and we cannot be hesitant to place a Hispanic student in an AP Calculus class. It is our job to give students all of their options, whether or not other educators believe this is possible or desirable. We can be the first line of defense against educational stereotypes, and we need to be in order to ensure a better education for all students.

\section{Certesa: Program Ideas for Diverse Populations}

Gibson, Gandara and Koyama's (2003) work illustrates that diverse student populations are often identified as groups that experience failure and fall behind their peers; this in turn leads diverse students to equate school with a negative environment that creates and reinforces their dissonant image of themselves. To be more specific, diverse students are often labeled "at-risk". Gibson, Gandara, and Koyama's work further indicates that this label defines minority students as low achievers who exhibit low self-esteem, do not experience success in school, and are potential dropouts. The work of counseling candidates must include the development and implementation of appropriate interventions designed to curb the self-fulfilling prophecies so commonly found in "at-risk" populations.

Counseling candidates in this study articulated that creating programs that better meet the needs of "at risk" minority students will likely increase the number of students who achieve the first significant educational milestone in their lives, which is to graduate from high school. Certesa, one of our candidates, suggested:

I believe that mentoring is very powerful in counseling. These students are in dire need of being heard and guided by someone they can look up to. Through a mentoring program, students are able to develop positive relationships that may be lacking in their lives.

Certesa felt that service-learning programs "can help 'at-risk' students develop a sense of belonging in their schools and communities...service learning is an educational technique that incorporates community service into the academic curriculum". Bridgeland, Dilulio, and Wulsin (2008) agree that service learning differs from generic community service in that it has specific academic goals, is organized through schools, and involves reflection activities for the participants. Certesa concluded that providing effective service learning program experiences for at-risk students is the responsibility of counselors. 
It is important to understand that school support is what will help "at-risk" students succeed in school. Certesa adds, "If there is one component missing for a population of "at risk" students, it is my responsibility as a counselor to provide services for this population; it is just a matter of the counselor tapping into these resources and applying the services appropriately." In the end, Certesa says, "It is not what I say to these students that will make a difference, but what I do for them that will make a change in their worlds".

\section{Carlos: Knowing the Community}

Schools often blame social problems like broken homes, bad parenting and poverty as excuses for their students' low academic test score performances and other indicators of underachievement. The impressions of Carlos, another counselor candidate in our program who took part in this project, reflect his familiarity with at-risk populations. For instance, he learned:

There was little or nothing being given back to the community, but the community was always quick to give themselves to the institutions. Whether it was a clinic, church, or even law enforcement, the population was void of hope or interest; thus, they turned to these establishments for comfort or relief.

The problem Carlos discovered is that "no one seeks out the institution of education to learn to deal with poverty and neglect. Instead they use the institution of education as a holding tank for a future population of lost children". The student population of the students with whom Carlos worked was primarily comprised of African Americans and Latinos. Although he states they are "very different in terms of language, food and customary issues, ... they all share a community that was poverty stricken". Further, Carlos states:

I came to an understanding of why there were so many people seemingly stagnant. People who are from below the poverty line... have nothing to look forward to...the children have no instructions in a world that requires you to follow and obey rules...most of these kids who are neglected come from a community that is being neglected by society.

Carlos' action plan based on his new, more holistic understanding of at-risk communities is to use "a systemic approach for reinforcing a child's positive behavior... [and] promote prosocial behavior among parents, students and teachers". He moved from feeling sympathy for poverty-stricken children and families to advocating for systemic change with a deep empathic understanding of what the lives of at-risk children and their communities are like. Carlos moved from having a passive reactive stance to being an active, proactive change agent in schools and communities.

\section{Summary}

What we found in the work of all candidates as a principle factor was a marked increase in 
the respect and appreciation for the diverse candidates they worked with as well as the cultural knowledge gained to meet the growing needs of diverse populations. The populations studied by candidates included African American, Latino and Asian students, foster students, at-risk students in alternative education schools, homeless students, and special education students. The points indicated in the work of candidates illustrate the marked instances of social injustices, academic roadblocks, discrimination, stereotyping, labeling and marginalizing that diverse groups of students in schools have historically dealt with in the public education system. Further, candidates recognized that the selffulfilling prophecies imposed upon diverse students by external societal and educational inputs have followed and continue to follow students, impairing their academic development.

\section{Conclusion}

This study is one component of a School Counseling Preparation Program within a College of Education and Organizational Leadership that has core values of caring, diversity, excellence, and leadership. Candidates in the program are asked to reflect on and address issues related to diversity and at-risk students in every class they take, culminating in 600 hours of fieldwork experience in the schools. The goal of this project is to deepen the empathic connection of candidates to the communities they will be working in.

Based on the comments of the candidates in this study, our conclusion is that understanding issues of social justice requires the deconstruction of popular myths about poverty and the oppressed as well as consideration of methods designed to break the cycle of oppression and poverty (Au, 2009). To effectively lead schools with diverse populations, this project provided candidates with a foundation for understanding the process of developing necessary empathy, skills and knowledge. Candidates reported significant shifts in their ability to understand students and their families when they immersed themselves in the worldview of the students. A deeper understanding led to empowerment and development of resources and skills they need to be effective counselors and advocates for students. Deconstructing cultural barriers led to development of relationships, familiarity and identification with what had been different or "other", opening the door to empathic joining and mutual empowerment through connection. We live in a global community with exponential increases in diverse experiences. It is clear that the current state of education in the U.S. is in dire need of reform, particularly as it relates to communities of diverse students. School counselors are front line professionals and active change agents and called on to negotiate the deconstruction of cultural barriers and negative stereotypes while maintaining a respect and appreciation for diverse populations of students and families. To better serve the needs of our richly diverse students, it is imperative that candidates in School Counseling Programs develop skills in mindfulness and empathic attunement.

Action research in the form of fieldwork in the schools involves immersion of candidates in the worldview of the students they are serving. Understanding grows from experience, and action plans develop from that understanding. This benefits students, 
families, and school communities, particularly in the areas of academic, career and personal and social success of students. Engagement in a deep self-reflection on that immersion, expansion of knowledge and resource bases, and development and implementation of active intervention and support plans are crucial to success in work with diverse populations.

\section{References}

Adelman, H., \& Taylor, L. (2002). School counselors and school reform: New directions. Professional School Counseling, 5(4), 235-248.

Anderson-Butcher, D., \&. Ashton, D. (2004). Innovative models of collaboration to serve children, youths, families, and communities. Children \& Schools, 26(1), 39-53.

American School Counselor Association. (2005). The ASCA national model: A framework for school counseling programs (2nd ed.). Alexandria, VA: American School Counselor Association.

$\mathrm{Au}, \mathrm{W}$. (2009). rethinking multicultural education: teaching for racial and cultural justice. Milwaukee, Wisconsin: A Rethinking Schools Publication.

Barrera, H. (2008, July 16). Trying to bridge the grade divide. Los Angeles Times. Retrieved from http://articles.latimes.com/2008/jul/16/local/me-lincoln16.

Bemak, F. (2000). Transforming the role of the counselor to provide leadership in educational reform through collaboration. Professional School Counseling, 3(5), 323-331.

Bridgeland, J., Dilulio, J., \& Wulsin, S. (2008). Engaged for success: Service learning as a tool for high school dropout prevention. Washington D.C.: Civic Enterprises. Retrieved from http://www.civicenterprises.net/pdfs/service-learning.

Bryan, J. (2005). Fostering educational resilience and achievement in urban schools through school-family-community partnerships. Professional School Counseling, 8(3), 219-227.

Christenson, S., \& Sheridan, S. (2001). Schools and families: Creating essential connections for learning. New York: Guilford Press.

Constantine, G., \& Yeh, J. (2001). Multicultural training, self-construals and multicultural competencies of school counselors. Professional School Counseling, 4(1), 202-207. 
Constantine, G., Arorash, T., Barakett, M., Blackmon, S., Donelly, P., \& Edles, P. (2001). School counselor's universal-diverse orientation and aspects of their multicultural counselor competence. Professional School Counseling, 5(1), 13-18.

Corey, G. (2004). Theory and practice of group counseling. Pacific, Grove, CA: Brooks \& Cole Publishing Company.

Creswell, J. W. (2007). Qualitative inquiry and research design: Choosing among five approaches. Thousand Oaks, CA: Sage Publications Inc.

Dahir, C., \& Stone, B. (2009). School counselor accountability: The path to social justice and systemic change. Journal of Counseling and Development, 87(1), 12-87.

DeLucia-Waak, J. (1996). Multiculturalism is inherent in all group work. Journal for Specialists in Group Work, 21(4), 218-223.

Denzin, N. \& Lincoln Y. (2003). Handbook of Qualitative Research. Thousand Oaks, CA: Sage Publications, Inc.

Dickson, G., Jepsen, D., \& Barbee, P. (2008). Exploring the relationships among multicultural training experiences and attitudes toward diversity among counseling students. Journal of Multicultural Counseling and Development, 36(2), 113-126.

Dickson, G., \& Jepsen, D. (2007). Multicultural training experiences as predictors of multicultural competencies: Students' perspectives. Counselor Education and Supervision, 47(2), 76-96.

Education Trust. (2007). Transforming school counseling: Benefits of becoming a transforming school counselor preparation program. Retrieved from the Education Trust website: http://www2.edtrust.org

Ellis, C., \& Bochner, A. P. (2000). Autoethnography, personal narrative, reflexivity: Researcher as subject. In Denzin, N.K. and Lincoln, Y.S. (Eds.), The handbook of qualitative research (2nd ed.) (pp.733-768). London, England: Sage Publications.

Elliott, J. (1991) Action research for school change. Philadelphia: Open University Press.

Epstein, J. (2008). Improving family and community involvement in secondary schools. The Education Digest, 73 (6), 9-12.

Epstein, J., \& Voorhis, F. (2010). School counselors' roles in developing partnerships with families and communities for student success. Professional School Counseling, 14, (1), 1-15. 
Erford, B. (2003). Transforming the school counseling profession. Upper Saddle River, NJ: Merill Prentice Hall.

Gibson, M., Gandara, P., \& Koyama, J. (2003). School connections: U.S. Mexican youth, peers, and school achievement. New York, NY: Teachers College Press.

Granello, D. H. (2000). Contextual teaching and learning in counselor education. Counselor Education and Supervision, 39(4), 270-283.

Green, A. G., Conley, J. A., \& Barnett, K. (2005). Urban school counseling: Implications for practice and training. Professional School Counseling, 8, 189-195.

Green, A., \& Keys, S. G. (2001). Expanding the developmental school-counseling paradigm: Meeting the needs of the 21st century student. Professional School Counseling, 5(2), 84-95.

Greenwood, D., \& Levin, M. (2007). Introduction to action research: Social research for social change. Thousand Oaks, CA: Sage Publications.

Guba, E. G., \& Lincoln, Y. S. (1989). Fourth generation evaluation. Beverly Hills, CA: Sage Publications Inc.

Gysbers, N. C. (2001). School guidance and counseling in the $21^{\text {st }}$ century: Remember the past into the future. Professional School Counseling, 5(1), 96-105.

Havercamp, B. E., \& Young, R. A. (2007). Paradigms, purpose and the role of literature: Formulating a rationale for qualitative investigations. The Counseling Psychologist, 35(2), 265-294.

Heidegger, M. (1962). Being and time (J. Macquarrie \& E. Robinson, Trans.). New York: Harper.

Herring, D. (1998). The future direction of multicultural counseling: An assessment of preservice school counselors' thoughts. Journal of Multicultural Counseling and Development, 26(2), 2-12.

Holcomb-McCoy, C. (1998). School counselor preparation in urban settings. (Eric Document Reproduction No. ED 418 343).

House, R. M., \& Hayes, R. L. (2002). School counselors: Becoming key players in school reform. Professional School Counseling, 5(4), 249-256. 
House, R., \& Martin, P. (1998). Advocating for better futures for all students: A new vision for school counselors. Education, 119(2), 284-291.

Kretzmann, J., \& McKnight, J. (1993). Building communities from the inside out: A path toward finding and mobilizing a community's assets. Chicago, IL: ACTA Publications.

Laverty, S. M. (2003). Hermeneutic phenomenology and phenomenology: A comparison of historical and methodological considerations. International Journal of Qualitative Methods, 2, Article 3. Retrieved January 24, 2009, from http://www. ualberta.ca/ iiqm/backissues/2_3final/html/laverty.html

Lincoln, Y. S., \& Guba, E. G. (1985). Naturalistic inquiry. Beverly Hills, CA: Sage Publications Inc.

Marshall, E., \& Toohey, K. (2010). Representing family: Community funds of knowledge, bilingualism, and multimodality. Harvard Educational Review, $80(2), 221-243$.

Martin, P. J. (2002). Transforming school counseling: A national perspective. Theory Into Practice, 41(3), 148-153.

Mason, E. (2008). The relationship between school counselor leadership practices and comprehensive program implementation (Doctoral Dissertation, Georgia State University). Retrieved from http://gradworks.umi.com/33/23/3323224.html

McNiff, J. (1988) Action research: Principles and practice. London: Macmillan.

Montes, A. (2007). Possible Selves: The role of peers and their influence in shaping Latino adolescent schooling and future academic outcomes (Doctoral Dissertation, Claremont Graduate University).

Retrieved from http://gradworks.umi.com/32/68/3268254.html

Moustakas, C. (1994). Phenomenological research methods. Thousand Oaks, CA:

Sage Publications Inc.

Paisley, P. O., \& McMahon, H. G. (2001). School counseling for the 21st century: Challenges and opportunities. Professional School Counseling, 5(2), 106-115.

Pedersen, P., \& Carey, J. (2003). Multicultural counseling in schools: A practical handbook. New York, NY: Pearson Education. 
Petr, C., \& Walter, U. (2005). Best practices inquiry: A multidimensional, value critical framework. Journal of Social Work Education, 41(2), 251-267.

Perusse, R., Goodnough, G., \& Noel, C. (2001). A national survey of school counselor preparation programs: Screening methods, faculty experiences, curricular content and fieldwork requirements. Counselor Education and Supervision, 40(4), 252262.

Pew Hispanic Center. (2005). Hispanics: A people in motion. Retrieved from http://pewhispanics.org/files/reports/40.pdf

Ponterotto, J. G. (2005). Qualitative research in counseling psychology: A primer on research paradigms and philosophy of science. Journal of Counseling Psychology, 52(2), 126-136.

Portes, A., \& Rumbaut, R. (1990). Immigrant America: A portrait. Berkeley, CA: University of California Press.

Sanders, M., \& Lewis, K. (2005). Building bridges toward excellence: Community involvement in high schools. The High School Journal, 88(3), 1-10.

Santiago-Rivera, A., Arredondo, P., \& Gallardo-Cooper, M. (2002). Counseling Latinos and la familia: A practical guide. Thousand Oaks, CA: Sage Publications.

Singh, A., Urbano, A., Haston, M., \& McMahon, E. (2010). School counselors' strategies for social justice change: A grounded theory of what works in the real world. Professional School Counseling, 13(3), 135-146.

Sue, D.W., Arredondo, P., \& McDavis, R.J. (1992). Multicultural counseling competencies: A call to the profession. Journal of Counseling and Development, $70(4), 477-486$.

Sue, D.W., \& Sue, D. (1990). Counseling the culturally different: Theory and practice. $\left(2^{\text {nd }}\right.$ Ed. $)$. New York, NY: Wiley.

Sue, D.W., \& Sue, D. (2008). Counseling the culturally diverse: Theory and practice. $\left(5^{\text {th }}\right.$ Ed.). New York, NY: Wiley.

Stahl, G. (2006). Group cognition. Cambridge, MA: MIT Press.

Suzuki, L. A., Ahluwalia, M. K., Arora, A. K., \& Mattis, J. S. (2007). The pond you fish in determines the fish you catch: Exploring strategies for qualitative data collection. The Counseling Psychologist, 35(2), 295-327. 
Tedlock, B. (2000). Ethnography and ethnographic representation. In Denzin, N.K. and Lincoln, Y.S. (Eds) The Handbook of Qualitative Research (2nd Ed.) (pp. 165213). London, England: Sage Publications.

Trevino, M. (2008, July). California high drop-out rates of Latino and Black students are not surprising - It's expected. Latina Lista. Retrieved from http:// www.latinalista.net.

Van Manen, M. (1990). Researching lived experience: Human science for an action sensitive pedagogy. Albany: State University of New York.

Zajda, J. (2005). International handbook on globalisation, education and policy research: Global pedagogies and policies. New York, NY: Springer. 